\title{
ALGORITHMS IMPROVING FLYING QUALITIES OF GENERAL AVIATION AIRCRAFT
}

\author{
T. Rogalski, B. Dołęga \\ Rzeszow University of Technology, Rzeszow,Poland.E-mail: orakl@prz.rzeszow.pl,dolbog@prz.rzeszow.pl \\ Received 1412 2004, accepted 09062006
}

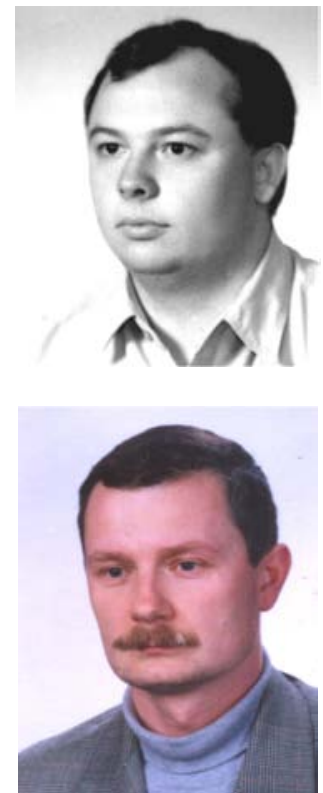

Tomasz ROGALSKI, PhD

Date and place of birth: 1972 in Tarnow, Poland.

Education: 1996 - Reshow University of Technology.

Affiliations and functions: 1996 - present - Aviation Department of Rzeszow University of Technology.

Research interests: Pilot friendly control system for small transportation plane.

Publications: About 30 articles.

Boguslaw DOLEGA, $\mathrm{PhD}$

Date and place of birth: 1962 in Jaslo, Poland.

Education: Rzeszow University of Technology.

Affiliations and functions: Rzeszow University of Technology, assistant; 1994 - PhD degree from the Department of Mechanical Engineering of Rzeszow University of Technology; since 1995 - Professor Assistant on Avionics and Control Systems Department at that University.

Research interests: Diagnostics aircraft navigation and control systems, with a focus on the development of the control theory for online fault detection and localization methods.

Experience: Co-organizer of Avionics Conferences.

Publications: Over 40 scientific articles.

Present position: Professor Assistant on Avionics and Control Systems Department at that University.

\begin{abstract}
The dynamic growth of general aviation as a mean of transport over medium distances means that people having no extraordinary qualifications or extraordinary physical or mental abilities more often pilot such types of airplanes. This phenomenon creates the necessity of giving planes flying qualities that allow them to be safely piloted by ordinary people. One way of solving this problem is equipping airplanes with fly-by-wire control systems that modify their handling qualities. Then the computer included into such control systems modifies the actions taken by the pilot, making the airplane both easier and more comfortable to control. This paper presents sample software tools - control algorithms that allowing an airplane's handling qualities to be improved. They are prepared by the authors and tested on board an experimental plane. That plane was equipped with a prototypical fly-by-wire control system, which can modify a plane's responses to a pilot's actions.

Selected results of flying tests of this control system that modifies handling qualities are presented in this paper. Those results were a starting point for investigations to rate and compare the handling qualities of a plane equipped with a control system working according to the algorithms tested.
\end{abstract}

Keywords: aircraft control system, handling qualities, flight tests.

\section{Introduction}

The evolution of aviation has always been strictly connected to the development of aviation science, material technology, and during the last decades also to informatics, electronics, and other disciplines of modern science. It can be said that thanks to activities in the above-mentioned fields, general aviation aircraft have became cheaper, safer, and easier to fly. A wider group of people has started using such planes as a means of local transport. This phenomenon leads to that the necessity of creating an airplane people having no extraordinary qualifications or very high level of aviation experience can fly safely.

One of elements required to realize this task is installing control systems in general aviation aircraft. So far classical mechanical control systems have been used for such types of planes. Recently research into the use of fly-by-wire control systems have started at many aviation research centers across the world.

The Avionics and Control Department of Rzeszow Technical University have undertaken similar activity. In the past few years, some projects to develop fly-by-wire 
(FBW) control systems and control laws used with them have been undertaken $[4,1]$. One of the tasks of the work performed has been to create and test control algorithms that allow an aircraft's handling qualities to be improved.

The paper brings up selected problems that were noticed when fly-by-wire control system was installed on board of the experimental general aviation plane.

\section{The structure of the experimentally tested control system}

The subject of research was the manual-computeraided control system (MCACS). In such control systems, the pilot controls the flight of the plane via the on-board computer (Fig 1). By using the control device (stick, ministick, side stick, etc.), the pilot does not move control surfaces directly but only gives orders to the on-board computer. The computer analyzing flight parameters and the pilot's commands creates controls for actuators moving control surfaces.

In practical realization described in this paper, MCACS consists of the following groups of elements:

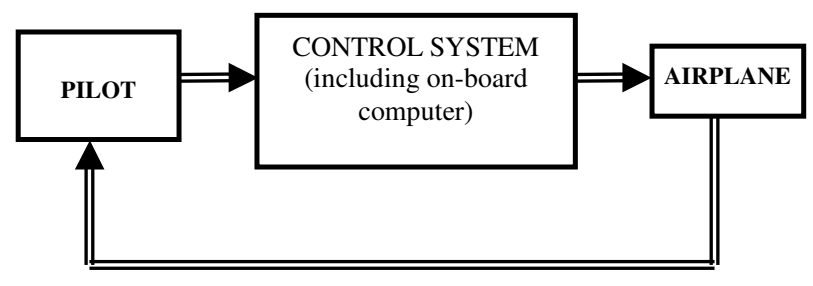

Fig 1. The schematic of manual-computer-aided control system

- main on-board computers,

- autonomous measurement devices,

- autonomous actuators,

- control, visualization and interface devices used to communicate between the pilot and the control system; in our case the experimental plane [5] was equipped with the side stick installed inside the cockpit enabling a right-hand pilot to fly the plane.

Because a direct mechanical connection does not exist between the control device and control surfaces, the pilot deflecting it does not feel a real force resulting from the plane's aerodynamic characteristics.

The aforementioned features of MCACS mean that a pilot's impressions while piloting planes with MCACS differ from those a pilot has when flying a plane equipped with a classical, mechanical control system [2, 3].

\section{The effect of exchanging the control system}

One of the problems taken into consideration was the question of how handling qualities would change if a fly-by-wire control system were used instead of a classical one.

In the first series of tests, the experimental airplane, which equipped with the mechanical control system had handling qualities recognized as very good and was described as very easy to fly by, was equipped with the tested fly-by-wire control system. The linear relationship between the position of the control device and control surfaces was kept. The maximal displacement of the control devices brought maximal displacements of control surfaces as determined for the original mechanical control system. As the control device, a side stick was used. Its revolving handle replaced pedals moving the rudder.

Opinions of pilots who took a part in test flights were that the, aircraft's handling qualities were degraded. The plane was even sometimes described, as difficult to fly. Its reactions to a pilot's commands were too nervous. The number of movements pilots performed during realization of sample test maneuvers increased compared to flights when the original control system was used (Fig 2).

The reasons for these phenomena were probably:

- Very small displacements of the handle of the side stick (about $5[\mathrm{~cm}]$ ) compared to the displacement of the handle of the original stick (about 50 [cm]).

- As mentioned above, there as no force feedback between aerodynamic forces and displacements of the side stick. Additionally, the pilot's forces necessary to move handle of the side stick were probably too small.

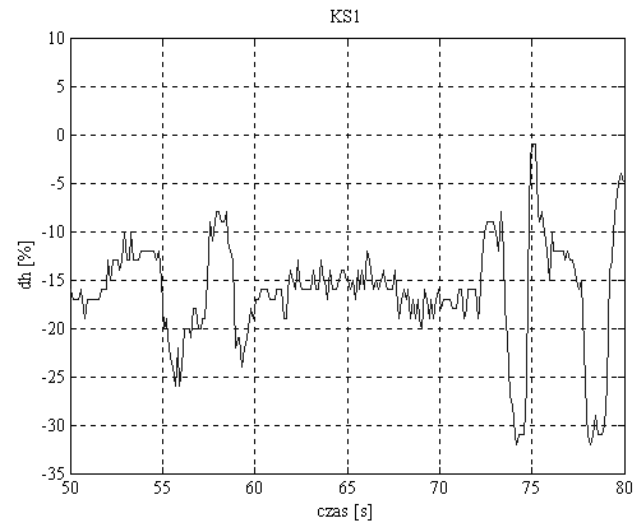

a)

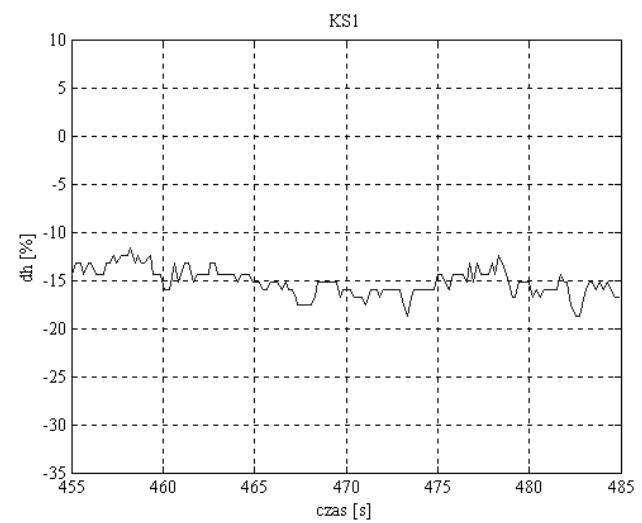

b)

Fig 2. During a sample maneuver of altitude stabilization there were more displacements of elevator having bigger amplitude in the case of the FBW control system a) then for the original mechanical one $b$ )

Initial test flights showed that it was necessary to create any means to improve the handling qualities of the aircraft. It was decided to prepare special control laws dependencies between displacements of side stick and an 
airplane's flight parameters to modify handling characteristics.

\section{Algorithms improving the handling qualities of the aircraft}

The first step to make the airplane less nervous was to reduce the value of the gain coefficient between the displacement of the side stick and the position of the related control surfaces. This can be realized in two ways: increasing the range of the handle displacements of the side stick or reducing the range of the displacements of the control surfaces. The aircraft's response to a pilot's commands then becomes softer but such a solution (especially the second one) makes it impossible to perform all dynamic maneuvers.

The test pilots participating in the project said that the best situation was when the plane was not very sensitive around the neutral position of the side stick but provided the possibility to reach the full range of projected positions of control surfaces in its extreme positions. Moreover, the neutral position of the side stick should lead to steady flight with zero bang angles. Such a solution gives a very accurate and soft reaction of the plane near the point of steady flight, enabling the performance of almost all types of maneuvers permitted.

The schematics of the control law working according to the foregoing rules are presented in figure 3 . Introducing specialized dependencies between the position of the side stick and control surfaces, the handling qualities of the aircraft can be formed.

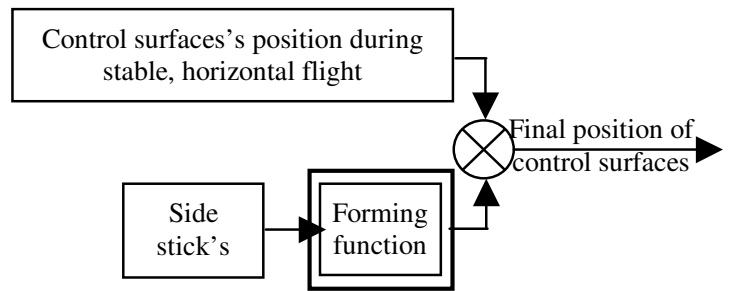

Fig 3. The schematic of control law using forming functions

To prevent the reaction of the aircraft to small accidental movements of the mini stick near its neutral position, a dead zone was introduced. Moreover, to meet pilots wishes, the nonlinear dependencies between the position of the stick and position of the control surfaces was realized. Sample forming functions satisfying the foregoing assumptions are presented in figure 4 and formulas (1) and (2).

$$
k(X)=\left\{\begin{array}{l}
k_{1} \text { for }|x|<a \\
k_{2} \text { for }|x| \geq a
\end{array} \Rightarrow \delta S=\left\{\begin{array}{c}
k_{2} x-a\left(k_{1}-k_{2}\right) \text { for } x>a \\
k_{1} x \text { for } x \in\langle-a ; a\rangle \\
k_{2} x+a\left(k_{1}-k_{2}\right) \text { for } x<-a
\end{array}\right.\right.
$$

$$
\delta S=\operatorname{sgn}(x) \delta S_{\max }\left(\frac{x}{x_{\max }}\right)^{2}
$$

$\delta \mathrm{S}-$ position of the control surfaces,

The foregoing solutions met pilots' expectations; they brought slow, light reactions of the aircraft near the neutral position of the side stick and enabled a full range of control surface displacements to be used.

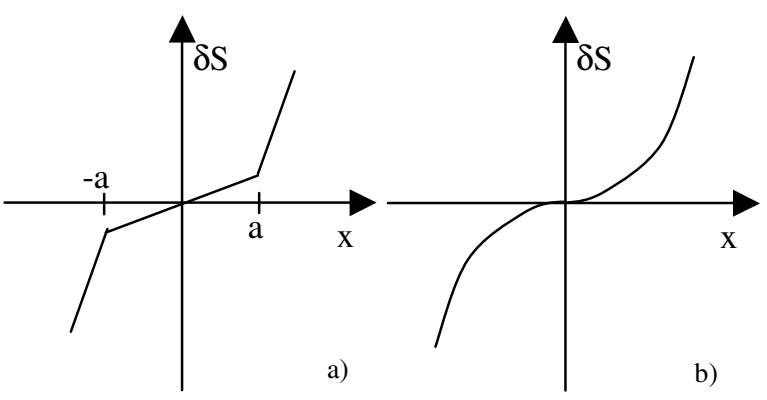

Fig 4. Sample forming functions bringing non-linear relation position of control surfaces from side stick's position; a) described by (1), b) described by (2)

After the forming functions presented had been used, a clear improvement in the handling qualities of the aircraft was observed (according to the subjective opinions of pilots). The calculated position of control surfaces does not, however, depend on the character of a pilot's activity. It means that both very soft and very dynamic movements of a pilot bring that same calculated positions of control surfaces. The above-mentioned problems become the starting point for an investigation of the control laws, taking into consideration the type of controls of a pilot.

If the signal controlling the deflection of the control surfaces in time, $\delta S(t)$, depends not only on stick position $X(t)$ but also on its movement rate $K_{d} \frac{d}{d t} X(t)$ (3), then the calculated value takes into consideration the character of a pilot's activity, his kind of control.

$$
\delta S(t)=\delta S_{T}+K(x) \cdot X(t)+K_{d} \frac{d}{d t} X(t)
$$

where $\delta S_{T}-$ position of control surfaces keeping straight steady flight.

A more sophisticated approach used fuzzy logic and expert knowledge to prepare the set of rules defining the dislocation of control surfaces. The properly composed set of rules can meet all requirements of pilots, including dead zone, non-linear gain, and character of the pilot's movements with the side stick (Fig 5).

The work of the above-mentioned algorithms was tested during test flights. Pilots were instructed to perform a series of identical test maneuvers. Those were typical maneuvers realized during standard operational conditions of a light general aviation plane (stabilization and reaching selected flight parameters, e.g. altitude, course, speed, attitude).

where: $\quad \mathrm{x}-$ mini stick's position, 


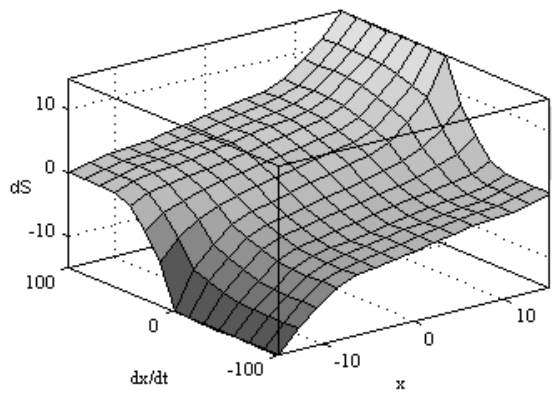

Fig 5. The sample surface illustrating dependencies between stick position $X$, its rate $d x / d t$ and position of control surfaces $d S$

The investigations carried out allow the following statement to be formed. "The properly chosen forming function can modify the handling qualities of the aircraft and it is recognized as easier to be piloted." The effect of the work of algorithms could be seen during the analysis of data recorded in experimental flights. Decreases in both the numbers of the movements of the stick and their amplitude were observed (Fig 6) the precision of control increased [3, 4].

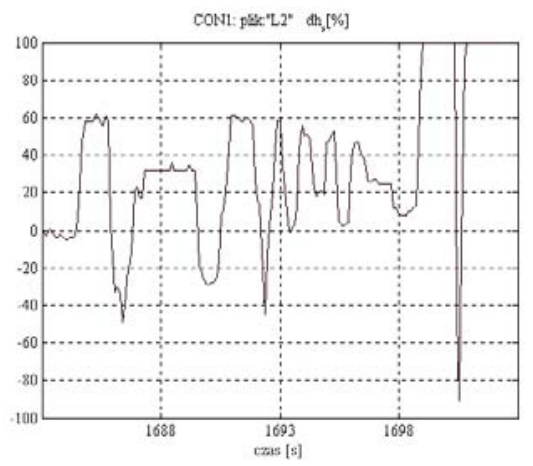

a)

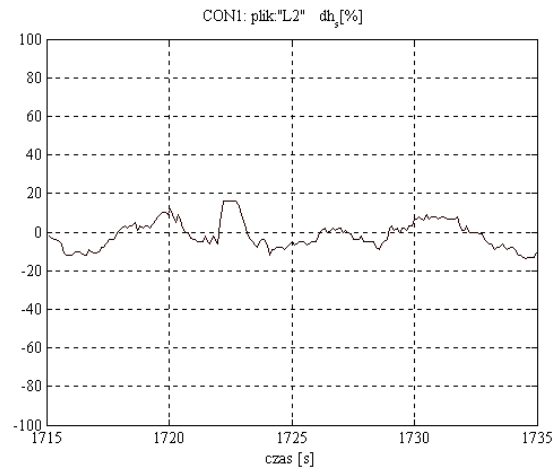

b)

Fig 6. The forming function using fuzzy logic (b), decreased the number and amplitude of the displacements of the side stick compared to control laws that were not augmented (a)

The Control algorithms presented above worked at the system: pilot - control devices - airplane, where the pilot played the role of the regulator. Pilot's activity was strictly connected to the stabilization process of selected flight parameters. The control loop was closed from the state of the aircraft to the activity of the pilot by human impressions and fillings.

The tests also included other kinds of control laws, when the role of the pilot was changed (Fig 7).
The pilot did not directly move control surfaces to keep the required values of selected flight parameters. He was rather a system operator. Via the side stick the pilot, ordered the system flight parameters he wanted to keep. And the automatic system did the rest. This means, for instance, the pilot setting the required pitch angle did not need to control flight parameters to stabilize it. That value of the pitch angle was automatically stabilized.

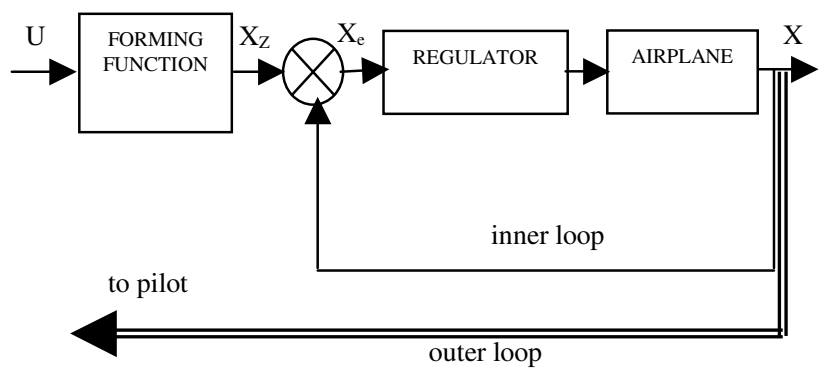

Fig 7. Schematic of control laws using regulators of selected flight parameters. $U$ - position of side stick, $X$ - stabilized value of selected flight parameter, $X_{z}-$ demand value of stabilized flight parameter, $X_{e}-$ stabilization error

The signal from the side stick via the special forming function was recalculated to the value of the selected flight parameter. This value was automatically stabilized by the inner loop of the control system.

In the cases tested, the following forms of control algorithms were used. In the longitudinal movement channel, the inner loop stabilized the demanded value of the pitch angle and the roll angle at the lateral movement. The forming function calculating proper flight parameter at the pitch channel had the following form (4)

$$
\Theta_{d}=\left.k \int X_{s} d t\right|_{\Theta \min } ^{\Theta \max }
$$

where: $\Theta_{\mathrm{d}}-$ demanded value of pitch angle,

$\mathrm{k}$ - integration coefficient,

Xs - signal from the stick processed by the dead zone,

$\Theta_{\min }, \Theta_{\max }-$ minimum and maximum permitted pitch angles.

This form of the control algorithm meant that the rate of the demanded value of the pitch angle was proportional to the position of the side stick. Putting the side stick into neutral position stopped rotation and the computer kept the value of the pitch angle that had been settled.

In the lateral channel of airplane motion, the control algorithms implemented had the same form as in the longitudinal one. But they concerned the aileron displacement and the bang angle control respectively.

The slide slip angle was automatically reduced to zero by the additional regulator system. The pilot did not need to take any action to do that. Sample results of tests for longitudinal mode of the motion of the plane is presented in table and graphs (Fig 8). 
Table. Tested control algorithms modified handling qualities of aircraft- sample parameters

\begin{tabular}{|c|l|c|c|c|}
\hline Symbol & \multicolumn{1}{|c|}{ Parameter [unit] } & $\begin{array}{c}\text { Direct } \\
\text { proportional } \\
\text { control }\end{array}$ & $\begin{array}{c}\text { Control with } \\
\text { the forming } \\
\text { function }\end{array}$ & $\begin{array}{c}\text { Control with the } \\
\text { controller of } \\
\text { pitch angle }\end{array}$ \\
\hline$S$ & Standard deviation of altitude $[\mathrm{m}]$ & 1.4 & 1.5 & 0.5 \\
\hline$S_{\text {teta }}$ & Standard deviation of pitch $\left[{ }^{\circ}\right]$ & 1.4 & 0.8 & 0.2 \\
\hline$S_{q}$ & Standard deviation of pitch rate [\%] & 3.9 & 1.3 & 1 \\
\hline$N$ & $\begin{array}{l}\text { Number of stick movements during time } \\
\text { unit [1/s] }\end{array}$ & 0.9 & 0.65 & $0 *$ \\
\hline$A$ & $\begin{array}{l}\text { Average amplitude of single movement of } \\
\text { stick [\%] }\end{array}$ & \multirow{2}{|c|}{63.9} & 11.5 & $0 *$ \\
\hline
\end{tabular}

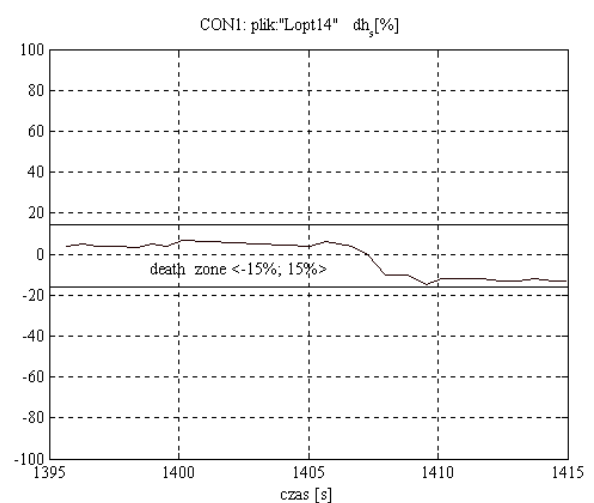

Fig 8. In the case of the control law with the pitch angle regulator, the pilot did not need to move the stick outside its dead zone to stabilize the altitude

The control law based on the pitch angle regulator modified the aircraft's handling qualities, forcing the pilot to change his technique of the pilotage. The pilot did not need to take any action to stabilize the space orientation of the aircraft. He only used the side stick to set values of flight parameters (especially space orientation angles) and his intentions were realized by the automatics. Small displacements of the side stick inside the dead zone $( \pm 15 \%)$ were rather randomly then caused by the pilot's intentional activity and were ignored by the control system.

The control law tested also influenced other parameters describing style of pilotage (some of them selected are included in table. Those parameters were used both to characterize and to compare the style of flight when different control laws were used. Analyzing these parameters, it can finally be said that algorithms augmenting the handling qualities of the aircraft caused the flight to be more stable and less nervous. And this situation led to a higher level of comfort and increased the flight safety [2].

Similar effects were reached for research of the lateral mode of airplane movement.

\section{Conclusion}

Flying tests showed that properly projected algorithms could modify an aircraft's handling qualities. The plane became easier to fly. They caused the behavior of the aircraft to be less nervous, characterized by less variation of space orientations angles.

A plane equipped with the algorithms described in this paper can be both easier and more safely piloted by people having no extraordinary features.

Algorithms augmenting an aircraft's handling qualities presented in this paper can be split into two groups. The first of them, which did not use any regulators of flight parameters, gives results that are maybe a little worse. They also did not need any devices to measure the flight parameters of the aircraft. The second group gave better results but required measuring several flight parameters, leading to more complicated structure of the control system. The additional necessary of an attitude and heading reference system (AHRS) and an aerodynamic data computer (ADC) increased the price of the system.

Finally, it can be said that the tests performed gave results, which allow supposing that the method of research was properly chosen. And investigation in this field will be continued in the future.

\section{References}

1. Kocks K. Systems that Permit Everyone to Fly // Avionics Magazine. - 2001 March. - P. 1620.

2. Rogalski T. The conception of control system allowing to modify small aircraft's properties and simulate another plane's behavior // AIAA Conference and Exhibition - Monterey, USA, 2002. - Paper No 3792.

3. Rogalski T., Dołęga B. Aircraft control system enabling fly to everybody // The 4-th International conference MECHANICS 2004. Scientific Bulletins of Rzeszow University of Technology. - Rzeszów 2004. - No 209.

4. Systemy sterowania i nawigacji bezzałogowych aparatów latających // Prace ZSS Politechniki Rzeszowskiej - grant KBN / Ed. J. Gruszecki. Rzeszów, 1998. - No 9T12C 08212 i 9T12C 01108/TA.

5. Tomczyk A. Experimental fly- by-wire control system for general aviation aircraft // AIAA GNC Conference, Austin TX, 2003. AIAA Paper. - 2003. - No 2003-5776. 